\title{
DETERMINATION OF LOW MOLECULAR WEIGHT CARBOHYDRATES IN CABERNET SAUVIGNON RED WINES
}

\author{
BETTY MATSUHIRO ${ }^{*}$, RODRIGO TORRES ${ }^{1}$, ELISA A. ZÚNIIGA ${ }^{1}$, MARIA J. AGUIRRE ${ }^{l}$, \\ LEONORA MENDOZA', MAURICIO ISAACS ${ }^{2}$
}

\author{
${ }^{1}$ Facultad de Química y Biología, Universidad de Santiago de Chile, Av. B. O'Higgins 3363, Santiago Chile. ${ }^{2}$ Facultad de Ciencias, \\ Universidad de Chile, Las Palmeras 3425, Santiago, Chile \\ (Received: March 17, 2009 - Accepted: September 28, 2009)
}

\begin{abstract}
Low molecular weight carbohydrates (LMW) were determined in a Chilean Cabernet Sauvignon red wine by the Dubois method, a specific method for the determination of carbohydrates. Dialysis treatment of red wine allowed the separation of pentoses, hexoses, reducing and non-reducing oligosaccharides and glycosides (LMW) from the polysaccharides fraction (HMW) fraction. The total sugar content of red wine by Dubois method was $5.55 \mathrm{~g} / \mathrm{L}$. The content of LMW sugars determined by Dubois method $(3.63 \mathrm{~g} / \mathrm{L})$ is higher than the sugar content of the polysaccharides fraction $(1.78 \mathrm{~g} / \mathrm{L})$. Analysis of twenty more samples of Cabernet Sauvignon red wines showed that the high molecular weight fraction content is quite iterative (mean value $2.50 \mathrm{~g} / \mathrm{L}$ ). The advantage of the Dubois method in relation to Fehling method is that the former does not need prior decolouration of the sample and there is not interference of aldehydes. The method developed in this work may be a complementary method for the determination of carbohydrates in wine industry.
\end{abstract}

Keywords: Reducing sugars, polysaccharides, red wine, Dubois method

\section{INTRODUCTION}

The main low mass carbohydrates in red wine are the reducing sugars glucose and fructose, some of which remain after fermentation. Also, the monosaccharides galactose, arabinose, ribose, rhamnose and xylose are present. In addition, red wines contain oligosaccharides such as sucrose and trehaloses ${ }^{1-3}$. The official Chilean method for the determination of reducing sugars in red wine is the titration procedure based on the Fehling method, by the reduction of an alkaline solution of copper (II) salt ${ }^{1,4}$. Samples must be previously decolourised to eliminate polyphenolic compounds. The official method proposed by European Community is similar and it is based on the iodometric determination of excess copper (II) after the reaction of sugars on a cupro-alkaline solution ${ }^{5}$. Glucose and fructose can be individually determined by spectrophotometric detection of the enzymatic phosphorylation and oxidation reactions, sucrose can also be estimated by this method after enzymatic hydrolysis ${ }^{1,5}$. Electrochemical procedures for the enzymatic determination of glucose and fructose were developed ${ }^{6-8}$. Sugars in wine can be determined by HPLC, using different detectors ${ }^{9-12}$. The addition of sucrose in red wine is allowed in many countries of the European Community, such as Germany, Belgium, Denmark, Ireland, Poland, Sweden, United Kingdom, Czech Republic and in some French departments ${ }^{13}$. In Chile, the import and marketing of European red wines containing sucrose is permitted ${ }^{14}$. Recently, concentrations of glucose and sucrose in red wine were determined by $1 \mathrm{D}$ and 2D NMR techniques ${ }^{15}$. Glucose, fructose and sucrose can be determined by capillary zone electrophoresis ${ }^{16}$.

Other low molecular weight carbohydrates are present in wine as glycosides of flavonoids and other phenolic compounds ${ }^{17,18}$. High molecular weight carbohydrates in red wine are originated either in grape berries (Vitis vinifera) or in yeast during fermentation. These compounds comprise neutral polysaccharides such as arabinogalactans, acidic pectic polysaccharides, and mannans associated with proteins ${ }^{19,20}$.

The Dubois method is an extremely versatile method for the determination of carbohydrates ${ }^{21}$. It is based on the prior conversion of sugars into furfural derivatives on heating with strong acids, followed by the formation of a coloured complex with phenol. This colorimetric method, also known as phenol-sulfuric acid method is used for the determination of free sugars, glycosides, oligosaccharides and polysaccharides ${ }^{22-26}$. Segarra et al. ${ }^{27}$ examined the polysaccharide levels in 27 musts from varieties of A.O.C. Penedès grapes, and the white wine samples obtained from those musts by Dubois method.

The aim of this work is to study the carbohydrate content in red wines, by the application of a specific method for carbohydrate quantification, the Dubois method. We performed a dialysis technique to separate low mass carbohydrate from polysaccharides in red wine; this fractionation allows the direct determination of the content of monosaccharides, oligosaccharides and soluble glycosides.

\section{MATERIALS AND METHODS}

Wine samples. Samples of Cabernet Sauvignon vintage 2005 red wine (CSW) were kindly supplied by a local producer. Additional eighteen commercial standard-quality Cabernet Sauvignon vintage 2005 wines from the Central valley of Chile, and two French Cabernet Sauvignon vintage 2006 wines were obtained in the local market. All the samples bottles were kept protected from sunlight at room temperature and opened at the moment of analysis. Reagent grade glucose, fructose, phenol, copper sulfate and concentrated $\mathrm{H}_{2} \mathrm{SO}_{4}$ were purchased from Merck (Darmstatd, Germany).

Fractionation of wine samples. Wine sample $(50 \mathrm{~mL})$ was introduced in a bag made from $20 \mathrm{~cm}$ of Spectra/Por (MWCO 3500) membrane of 2.9 $\mathrm{cm}$ diameter (Spectrum Laboratories Inc., USA) and was dialysed against one litre of distilled water under magnetic stirring for $1 \mathrm{~h}$. The colorless diffusate solutions and the red retentate solution were separately concentrated in vacuo to a final volume of $5 \mathrm{~mL}$, giving low molecular weight (LMW) and high molecular weight (HMW) fractions, respectively. The dialysis process was repeated two more times.

To test the recovery in the dialysis process, an aqueous solution $(50 \mathrm{~mL})$ containing $0.200 \mathrm{~g}$ of D-glucose and $0.125 \mathrm{~g}$ of dextran of MW 70,000 (Dextran T 70, Pharmacia Fine Chemicals, Uppsala, Sweden) was fractionated as above. All the dialysis was conducted in quadruplicate.

Dubois method. Carbohydrate content in wine samples and their fractions, was determined by Dubois method as described by Chaplin ${ }^{28}$. Briefly, $10 \mathrm{~mL}$ of wine sample was diluted to $100 \mathrm{~mL}$ in distilled water. To an aliquot $(0.5 \mathrm{~mL})$ of the solution, $0.5 \mathrm{~mL}$ of $5 \%$ aqueous solution of phenol in water was added, and then $2.5 \mathrm{~mL}$ of concentrated sulfuric acid was directly added to the surface of the solution. The reagents were added using Chempette bench dispensers (Cole Parmer, U.S.A.) of 2.0 and $10.0 \mathrm{~mL}$, respectively. After $20 \mathrm{~min}$, the absorbance was determined at $490 \mathrm{~nm}$ in a Genesys 5 (ThermoSpectronic, U.S.A.) spectrophotometer. A blank was prepared using distilled water instead of the wine solution. The amount of sugars was determined by reference to a standard curve prepared with solutions containing up to $12 \mu \mathrm{g} / \mathrm{mL}$ of D-glucose. For reproducibility the absorbance of wine sample was registered on a JASCO V-5380 spectrophotometer (JASCO, Japan). In the case of HMW and LMW extracts, the concentrated solution $(5 \mathrm{~mL})$ was diluted to $100 \mathrm{~mL}$ in distilled water. Then, one $\mathrm{mL}$ of the resulting solution was diluted to $100 \mathrm{~mL}$ in distilled water, and the determination was conducted on aliquots of $0.5 \mathrm{~mL}$. Experiments were run in sextuplicate.

Interference of anthocyanins on Dubois method. a) An aqueous solution $(50 \mathrm{~mL}$ ) containing $0.035 \mathrm{~g}$ of anthocyanins obtained by extraction of skins of Vitis vinifera grapes (Aguirre, Isaacs, Matsuhiro, Mendoza, and Torres, unpublished results) was submitted to fractionation process as wine samples. The carbohydrate content was determined as in the case of HMW and LMW extracts. Experiment was run in duplicate. b) To $7 \mathrm{~mL}$ of CSW wine, $3 \mathrm{~mL}$ of the anthocyanin extract $(3.03 \mathrm{mg} / \mathrm{mL})$ was added. The resulting solution was 
analysed by Dubois method. Determinations were run in quadruplicate.

Enzymatic methods for the determination of glucose, and fructose. Determinations in quadruplicate were conducted according to Bordeu and Scarpa ${ }^{1}$. Glucose was determined by the hexokinase, glucose-6-phosphate dehydrogenase assay using a kit from Calbiochem (Merck Biosciences, Darmstadt, Germany). After the glucose content was determined, phosphoglucose isomerase kit from Sigma (St. Louis, USA) was added for the determination of fructose.

Determination of reducing sugars by Fehling method. Determination was carried out according to Bordeu and Scarpa ${ }^{1}$. The wine sample $(100 \mathrm{~mL})$ was previously treated with $0.5 \mathrm{~g}$ of activated charcoal (Merck, Darmstatd, Germany), and centrifuged on a Universal 32 Hettich centrifuge at $8000 \mathrm{x}$ g.

Adsorption of glucose on charcoal. A solution containing $0.5 \mathrm{~g}$ of D-Glucose in $100 \mathrm{~mL}$ of water was stirred 10 min with $5.0 \mathrm{~g}$ of activated charcoal (Merck, Germany), the mixture was separated by centrifugation on a Universal 32 Hettich centrifuge at $8000 \mathrm{x}$ g, and filtered through a sintered funnel in vacuo. Glucose was determined in the supernatant by the Fehling method. Experiment was run in duplicate.

Statistical analysis. Statistical analysis of the obtained data were carried out by variance analysis (ANOVA), using STATISTICA 5.5 software version, Statsoft, U.S.A. A confidence interval $(\mathrm{CI})$ of $90 \%(\mathrm{p}<0.05)$ was used.

\section{RESULTS AND DISCUSSION}

Dialysis treatment allows the separation of carbohydrates with molecular weight lower than 3500 , herein called LMW fraction which diffuse into water while inside the membrane high molecular weight carbohydrates (HMW) and deep red water-insoluble compounds are retained. The phenol-sulfuric acid spectrophotometric method of Dubois was adapted for the determination of LMW and HMW carbohydrates in red wine. The linearity on a calibration curve was checked ranging from 1.5 to $12.0 \mu \mathrm{g} / \mathrm{mL}$ for D-glucose (Fig 1.).

According to Chaplin ${ }^{28}$ the sensitivity of the method is $1-60 \mu \mathrm{g}$ in $200 \mu \mathrm{L}$ of solution. A value of $0.21 \mu \mathrm{g} / \mathrm{mL}$ was obtained for limit of detection (LOD), which was determined measuring 10 times the absorbance of the blank, during one day, according to Skoog et al. ${ }^{29}$. A value of $0.42 \mu \mathrm{g} / \mathrm{mL}$ was obtained for the limit of quantification (LOQ), which was calculated according to Miller and $\operatorname{Miller}^{30}$ (Fig. 1). Repeatability and reproducibility were evaluated from the results obtained by two analysts working on the same sample, in quadruplicate, during three days (Table 1).

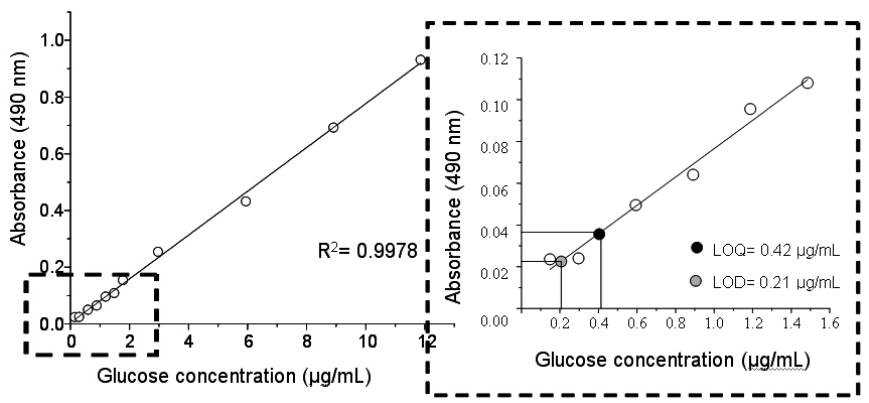

Figure 1. Glucose calibration curve and linearity parameters

In order to determine whether anthocyanins interfere in the determination of low molecular weight carbohydrates, solutions containing quantities of anthocyanins similar to that present in red wine samples, were submitted to fractionation by dialysis and analysed as the LMW and HMW fractions. The Dubois method gave values of $0.02 \pm 0.010 \mathrm{mg} / \mathrm{mL}$ for HMW fraction, 0.05 $\pm 0.004 \mathrm{mg} / \mathrm{mL}$ for LMW, and $0.08 \pm 0.005 \mathrm{mg} / \mathrm{mL}$ for total carbohydrates determined prior the dialysis fractionation, which indicated that interference by anthocyanins is not significant. In addition, a CRS wine sample containing double amount of anthocyanins was prepared by addition of anthocyanin extract to CRS wine. Determination of total sugars by Dubois method gave $5.95 \pm 0.12 \mathrm{~g} / \mathrm{L}$ for the spiked sample and $5.88 \pm 0.45 \mathrm{~g} / \mathrm{L}$ for the original wine. Furthermore, the possible interference in the determination of low molecular weight carbohydrates separated by the dialysis fractionation might be diminished since the coloured compounds remained in the retentate. In wine samples containing greater amounts of anthocyanins than CRS wine, a previous treatment with lead acetate may be used to avoid interferences by anthocyanins in the determination of sugars in high molecular weight fraction. But, the contribution of sugars from glycosides to total sugars would be lost.

Table 1. Repeatability and reproducibility of the carbohydrate content in the analysis of CSR red wine.

\begin{tabular}{|c|c|c|c|c|}
\hline Sample & $1 \mathrm{~A}(\mathrm{~g} / \mathrm{L})^{*}$ & $2 \mathrm{~A}(\mathrm{~g} / \mathrm{L})$ & $1 \mathrm{~B}(\mathrm{~g} / \mathrm{L})$ & $2 \mathrm{~B}(\mathrm{~g} / \mathrm{L})$ \\
\hline Total & $5.75 \pm 0.10$ & $5.55 \pm 0.31$ & $6.03 \pm 0.17$ & $5.81 \pm 0.24$ \\
\hline HMW & $2.01 \pm 0.03$ & $1.91 \pm 0.10$ & $2.02 \pm 0.02$ & $1.94 \pm 0.10$ \\
\hline LMW & $3.17 \pm 0.07$ & $3.09 \pm 0.01$ & $3.17 \pm 0.05$ & $3.13 \pm 0.01$ \\
\hline
\end{tabular}

*1A: Content obtained by analyst 1 , on Genesys 5 spectrophotometer, 2A: by analyst 2 on Genesys 5 spectrophotometer, 1B: by analyst 2 on Jasco V-530 spectrophotometer, 2B: by analyst 2 on Jasco V-530 spectrophotometer. HMW: High molecular weight carbohydrates, LMW:Low molecular weight carbohydrates. Determinations were conducted in quadruplicate.

The contents of carbohydrates in Cabernet Sauvignon red wine (CSR) is presented in Table 2. The value for reducing sugars obtained by the Fehling method is lower than that found for LMW fraction by the Dubois method. In the Fehling method, the wine sample should be previously decoloured, in the decolouration step, a considerable amount of solutes may be lost by adsorption on charcoal. We found that $75 \%$ of glucose is lost when a $0.5 \%$ aqueous solution of glucose is treated with charcoal in conditions similar to those of Fehling method. It can be pointed out that in the European Community decolouration of red wine is conducted using lead acetate ${ }^{5,31}$. By the Dubois method not only reducing sugars but oligosaccharides, glycosides and polysaccharides, which may be hydrolysed giving sugars that form furfural derivatives are determined. Being glucose and fructose, the most important reducing sugars of low molecular weight, their content was determined by enzymatic methods (Table 2). According to Moro et al. ${ }^{32}$ the content of fructose and glucose in standardquality red wines is higher than in high-quality ones. The formers may contain an average of $4.5 \mathrm{~g} / \mathrm{L}$ of fructose and $2.0 \mathrm{~g} / \mathrm{L}$ of glucose. The Chilean CSR red wine contains small amounts of these monosaccharides.

Table 2. Sugar contents in CSR red wine determined by Fehling and Dubois methods.

\begin{tabular}{|c|c|}
\hline Carbohydrates & Content $(\mathrm{g} / \mathrm{L})^{\mathrm{a}}$ \\
\hline Reducing sugars by Fehling method & $2.70 \pm 0.20$ \\
\hline Total sugars by Dubois method & $5.55 \pm 0.31$ \\
\hline Total sugars (after decolouration) by Dubois method & $4.21 \pm 0.62$ \\
\hline $\begin{array}{c}\text { High molecular weight fraction (HMW) by Dubois } \\
\text { method }\end{array}$ & $1.78 \pm 0.09$ \\
\hline $\begin{array}{c}\text { Low molecular weight fraction (LMW) by Dubois } \\
\text { method }\end{array}$ & $3.63 \pm 0.32$ \\
\hline Glucose by enzymatic method & $0.33 \pm 0.02$ \\
\hline Fructose by enzymatic method & $0.68 \pm 0.08$ \\
\hline
\end{tabular}

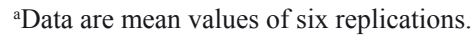

On the other hand, the Fehling method is used for the characterization of aliphatic aldehydes and is based on the oxidation of aldehyde function to carboxylic acids ${ }^{33}$. In wine, acetaldehyde is formed during vinification process and constitutes the most important carbonyl compound ${ }^{34}$. Ghica et al. ${ }^{35}$, recently found using bienzymatic biosensor that the acetaldehyde content in red wine varies between $106-187 \mathrm{mg} / \mathrm{L}$. This reducing compound is bind with free $\mathrm{SO}_{2}$ in wine, but at the temperature of Fehling reaction the bisulfite-acetaldehyde addition product liberates acetaldehyde which is oxidized by copper (II) ion. The advantage of the Dubois method is that it does not need prior decolouration of the sample and there is not interference of aldehydes. Furthermore, this method allows the quantification of non-reducing oligosaccharides, such as trehaloses and sucrose, which in the strong acidic medium employed in the reaction are hydrolyzed to reducing monosaccharides. From Table 2, in 
comparison with the value determined prior to the fractionation, it can be deduced that the recovery of low and high molecular weight carbohydrates through the separation by dialysis is very good. In a separate experiment, glucose and MW 70,000 dextran were used for the recovery test, and the sugar content was determined by the Dubois method. The recovery rate for glucose $(0.198 \pm 0.0069 \mathrm{~g})$ was $99 \%$, and for dextran $(0.121 \pm 0.0081 \mathrm{~g})$ was $97 \%$. Furthermore, the content of high molecular weight carbohydrates obtained by dialysis separation is in agreement with the amount obtained in this laboratory by liquid-liquid extraction of CSR red wine $(1.6 \mathrm{~g} / \mathrm{L})^{26}$.

The carbohydrate contents of additional eighteen samples of Chilean and of two French Cabernet Sauvignon red wines were analysed by Dubois method. Results presented on Table 3 indicate that the contents of high molecular weight carbohydrate fraction in the wine samples are very similar with an average value of $2.50 \mathrm{~g} / \mathrm{L}$. Furthermore, the contents of glucose and fructose in sample $9(0.21 \pm 0.01,0.44 \pm 0.02$, respectively $)$ and in sample $10(0.29 \pm 0.00,0.60$ \pm 0.01 ) determined by enzymatic methods show good correlations with the values found for CSR sample; the content of fructose doubles glucose content.

Application of Dubois method in the determination of low molecular weight carbohydrates present in Cabernet Sauvignon red wines gave reliable and reproducible results. In contrast with the HPLC and NMR methods, this spectrophotometric method is low cost and easy to handle procedure.

Table 3. Sugar contents in Cabernet Sauvignon wines by Dubois method ${ }^{a}$

\begin{tabular}{|c|r|r|r|}
\hline Sample & Total sugars $(\mathrm{g} / \mathrm{L})$ & $\mathrm{LMW}^{\mathrm{b}}(\mathrm{g} / \mathrm{L})$ & $\mathrm{HMW}^{\mathrm{c}}(\mathrm{g} / \mathrm{L})$ \\
\hline & & & \\
& & & \\
1 & $7.36 \pm 0.02$ & $4.64 \pm 0.04$ & $2.84 \pm 0.03$ \\
2 & $5.45 \pm 0.01$ & $3.06 \pm 0.01$ & $2.20 \pm 0.02$ \\
3 & $5.74 \pm 0.03$ & $3.49 \pm 0.02$ & $1.87 \pm 0.01$ \\
4 & $5.85 \pm 0.18$ & $3.14 \pm 0.06$ & $2.64 \pm 0.04$ \\
5 & $7.08 \pm 0.02$ & $3.67 \pm 0.06$ & $3.07 \pm 0.05$ \\
6 & $7.74 \pm 0.07$ & $4.56 \pm 0.08$ & $3.05 \pm 0.01$ \\
7 & $5.78 \pm 0.08$ & $3.27 \pm 0.02$ & $2.32 \pm 0.08$ \\
8 & $6.34 \pm 1.57$ & $4.58 \pm 1.28$ & $1.63 \pm 0.05$ \\
9 & $5.48 \pm 0.24$ & $2.51 \pm 0.03$ & $2.58 \pm 0.02$ \\
10 & $6.35 \pm 0.05$ & $3.49 \pm 0.00$ & $2.56 \pm 0.00$ \\
11 & $10.41 \pm 0.19$ & $7.98 \pm 0.98$ & $2.62 \pm 0.01$ \\
12 & $6.12 \pm 0.04$ & $3.29 \pm 0.00$ & $2.61 \pm 0.04$ \\
13 & $7.98 \pm 0.01$ & $5.19 \pm 0.29$ & $2.48 \pm 0.02$ \\
14 & $6.02 \pm 0.15$ & $2.91 \pm 0.16$ & $2.31 \pm 0.14$ \\
15 & $6.45 \pm 0.03$ & $3.21 \pm 0.00$ & $2.43 \pm 0.28$ \\
16 & $6.63 \pm 0.01$ & $3.37 \pm 0.02$ & $3.12 \pm 0.01$ \\
17 & $5.58 \pm 0.01$ & $3.61 \pm 0.02$ & $1.84 \pm 0.04$ \\
18 & $8.43 \pm 2.11$ & $5.36 \pm 0.40$ & $2.78 \pm 0.29$ \\
19 & $4.96 \pm 0.45$ & $2.63 \pm 0.06$ & $2.35 \pm 0.08$ \\
20 & $9.15 \pm 0.55$ & $6.44 \pm 0.77$ & $2.12 \pm 0.05$ \\
Mean & & & $\mathrm{p}$ \\
& & & $2.50 \pm 0.18$ \\
& & & $\mathrm{p}<0.05$ \\
\hline
\end{tabular}

a Data are mean values of four replications. ${ }^{b}$ Low molecular weight carbohydrates. ${ }^{\mathrm{c} H i g h}$ molecular weight carbohydrates. Samples 19 and 20 correspond to French Cabernet Sauvignon red wines.

\section{CONCLUSIONS}

It may be proposed that the adaptation of the Dubois method developed in this work may be a procedure for quantifying low molecular mass carbohydrates in red wine. The method is specific for carbohydrates, simple, accurate and it offers the advantage that no previous decolouration of the red wine is necessary. Furthermore, the total content of carbohydrates including glycosides and polysaccharides could be determined directly. In addition, for a particular brand of wine, the content of high molecular weight fraction could be determined after the dialysis procedure, and this value may be used in a routine analysis of low molecular red wine employing the Dubois method, as the correction factor. The method developed in this work may be a complementary method for the determination of carbohydrates in wine industry.

\section{ACKNOWLEDGMENT}

The financial support of Proyecto Anillo en Ciencia y Tecnología ACT-24 is gratefully acknowledged.

\section{REFERENCES}

1. S. E Bordeu, J. Scarpa. Análisis químico del vino, Second Edition, Ediciones Universidad Católica de Chile, Santiago, 2004.

2. B. W. Zoecklein, K. C. Fugelsang, B. H. Gump, F. S. Nury. Análisis y producción de vino. Editorial Acribia, Zaragoza, 2001.

3. S.-Q. Liu, C. R. Davis, Am. J. Enol. Vitic. 45, 229 (1994).

4. J. Staněk, M. Černý, J. Kocourek, J. Pacák. 1963. The monosaccharides. Academic Press, New York, 1963.

5. M. D. Luque de Castro, J. González-Rodríguez, P. Pérez-Juan. Food Rev. Inter. 21, 231 (2005).

6. L. Moio, A. Gambuti, L. Di Marzio, P. Piombino, Am. J. Enol. Vitic. 52, 271 (2001).

7. M. Esti, G. Volpe, D. Campagnone, G. Mariotti, D. Moscone, G. Palleschi, Am. J. Enol. Vitic. 54, 39 (2003).

8. Z. L. Chen, D. B. Hibbert, J. Chromatogr. A 766, 7 (1997).

9. R. Vonach, B. Lendl, R. Kellner, J. Chromatogr. A 824, 159 (1998).

10. A. Edelmann, C. Ruzicka, J. Frank, B. Lendl, W. Schrenk, E. Gornik, G. Strasser, J. Chromatogr. A 934, 123 (2001)

11. R. L.Cataldi, D. Nardiello, J. Agric. Food Chem. 51, 3737 (2003).

12. C. Martínez Montero, M. D. C. Rodríguez Dodero, D. A. Guillén Sánchez, C. García Barroso. J. Agric. Food Chem. 53, 1058 (2005).

13. Regulations. Official Journal of the European Union, 52 (2008).

14. Tratado de Asociación Unión Europea-Chile. Acuerdo sobre comercio de vinos. Anexo V, artículo 17 (2000).

15. L. Viggiani, M. A. Castiglione Morelli, J. Agric. Food Chem. 56, 8273 (2008).

16. X. Cheng, S. Zhang, H. Zhang, Q. Wang, P. He, X. Fang, Food Chem. 106, $830(2008)$.

17. J. Burns, W. Mullen, N. Landrault, P. Teissedre, M. Lean, A. Crozier, $J$. Agric. Food Chem. 50, 4096 (2002).

18. R. Lamuela-Reventós, A. Romero-Pérez, A. Waterhouse, M. TorreBoronat, Phytochemistry 42, 1591 (1996).

19. S. Vidal, P. Williams, T. Doco, M. Moutounet, P. Pellerin. Carbohydr Polym. 54, 439 (2003).

20. Z. Guadalupe, B. Ayestarán, J. Agric. Food Chem. 55, 10720 (2007).

21. M. K. Dubois, A. Gilles, J. K. Hamilton, P.A. Rebers, F. Smith, Anal. Biochem. 44, 628 (1956).

22. B. Matsuhiro, L. C. Presle, C. Sánchez, C. Urzúa, J. Chil.Chem. Soc. 51, 809 (2006)

23. H.-J. Zhang, W.-J. Mao, F. Fang, H.-Y. Li, H.-H. Sun, Y. Chen, X.-H. Qi, Carbohydr. Polym. 71, 428 (2008).

24. N. P. Chandía, B. Matsuhiro, Int. J. Biol. Macromol. 42, 235 (2008).

25. X. Zhang, L. Yu, H. Bi, X. Li, W. Ni, H. Han, N. Li, B. Wang, Y. Zhou, G. Tai, Carbohydra. Polym. 77, 544 (2009).

26. M. J. Aguirre, M. Isaacs, B. Matsuhiro, L. Mendoza, E. A. Zúñiga, Carbohydr. Res. 344, 1095 (2009).

27. I. Segarra, C. Lao, E. López-Tamames, C. De La Torre-Boronat, Am. J. Enol. Vitic. 46, 564 (1995).

28. M. F. Chaplin in Carbohydrate Analysis. M. F. Chaplin, J. F. Kennedy eds. IRL Press, Oxford, 1986; pp. 1-36.

29. D. A. Skoog, J. F. Holler, T. A. Nieman. Principios de análisis instrumental, McGraw-Hill/Interamericana de España, Madrid, 2000.

30. J. N. Miller, J.C. Miller. Estadística y Quimiometría para Química Analítica, $4^{\text {th }}$ Edition, Pearson Educación, Madrid, 2000.

31. Reglamento Comisión Comunidad Económica Europea N $N^{\circ}$ 2676/90 (1990).

32. E. Moro, R. Majocchi, C. Ballabio, S. Molfino, P. Restani, Am. J. Enol. Vitic. 58, 279 (2007)

33. A. I. Vogel, B. S. Furniss, A. J. Hannaford, P. W. G. Smith, A. R. Tatchell. Text book of practical organic chemistry, Fifth Edition. Longman Scientific and Technical, London, 1989.

34. S. Q. Liu, G. J. Pilone. Inter. J. Food Sci. Technol. 35, 49 (2000).

35. M. E. Ghica, R. Paulinkaite, N. Marchand, E. Devie, C. M. A. Brett. Anal. Chim. Acta, 591, 80 (2007). 